\title{
Management of the impalpable testis: the role of laparoscopy
}

\author{
C T Baillie, G Fearns, L Kitteringham, R R Turnock
}

\begin{abstract}
Purpose-To evaluate the use of laparoscopy in the management of the impalpable testis.

Design-A retrospective analysis of the clinical findings, interventions, and outcome in 87 consecutive boys undergoing laparoscopy for 97 impalpable testes.

Results-Fifty seven testes were either absent $(n=35)$ or present as a small remnant $(n=22)$, which was removed at contemporaneous groin exploration. There were 27 intra-abdominal testes, including four hypoplastic testes, which were removed laparoscopically. The 13 remaining viable testes were located in the groin. Conventional orchidopexy followed laparoscopy for 21 testes, and was successful in 17 cases. Two stage laparoscopically assisted Fowler Stevens orchidopexies were performed for 13 intra-abdominal testes, with eight satisfactory results. Ultrasound evaluation significantly reduced the number of conventional orchidopexies following laparoscopy.

Implications-Laparoscopy is a rational and safe approach for precise localisation of the impalpable testis. Laparoscopically assisted two stage orchidopexy is a successful treatment procedure for intraabdominal testes.

(Arch Dis Child 1998;79:419-422)
\end{abstract}

Keywords: laparoscopy; impalpable testis; orchidopexy

The initial assessment of the cryptorchid child may be by a variety of health care professionals and, consequently, referral patterns for surgical treatment vary. There is an increasing tendency to manage the impalpable testis by both diagnostic and therapeutic laparoscopy. However, successful operative management of the impalpable testis is clearly possible without recourse to laparoscopy. ${ }^{1-3}$ The purpose of our study was to analyse critically both the laparoscopic findings, and the results of laparoscopic interventions, after the introduction of the technique in a paediatric surgical centre. A management strategy is suggested for both unilateral and bilateral impalpable testes.

Paediatric Surgery,

Royal Liverpool Children's Hospital,

Alder Hey, Eaton Rd, Liverpool L12 2AP, UK C T Baillie

G Fearns

L Kitteringham

R R Turnock

Correspondence to: Mr Baillie.

Accepted 24 June 1998 A rethods admitted to the Royal Liverpool Children's Hospital, Alder Hey, who had undergone laparoscopy because one or both of their testes were impalpable. The following details were recorded: the mode of referral, results of ultrasound examination (if performed), the findings at laparoscopy, and details of any laparoscopic or open operative procedures performed.

In all patients, a $10 \mathrm{~mm}$ camera port was inserted in a subumbilical position using an open technique. A single $5 \mathrm{~mm}$ port was occasionally required in the contralateral iliac fossa to manipulate either bowel or testis with forceps. A further $10 \mathrm{~mm}$ port was used if laparoscopic clipping and division of the testicular vessels were performed as the first part of a two stage laparoscopically assisted Fowler Stevens orchidopexy. Second stage orchidopexy was performed six months later through a high groin incision, mobilising the testicle on its vasal pedicle, and frequently routing the testicle medial to the inferior epigastric artery (Prentiss manoeuvre).

All patients undergoing orchidopexy were reviewed two and six months after the procedure to assess the outcome of surgery. At the six monthly review, the position of the testis was assessed as low scrotal, high scrotal, or inguinal, and its size as unchanged or reduced.

\section{Results}

Laparoscopy was performed on 87 consecutive boys (median age, 46 months; range, 17-185), over a six year period by a single surgeon. All patients were admitted overnight, and there were no complications following laparoscopy. Seventy seven patients had unilateral, and 10 patients had bilateral undescended testes, making a total of 97 undescended testes (left sided, 65; right sided, 32). Sixteen patients had been referred by surgical colleagues after negative groin exploration. In this group, seven intraabdominal testes were found at laparoscopy.

Ultrasound examination of the groin was performed in 35 instances of impalpable testis. Laparoscopy was performed without use of previous ultrasound examination for the remaining 62 impalpable testes. After laparoscopy, conventional orchidopexies were performed for three canalicular or emergent testes in the former group, and 18 canalicular or emergent testes in the latter group. Thus, the requirement for conventional orchidopexy following laparoscopy was reduced significantly when preoperative ultrasound had been performed ( $p=0.02$, Fisher's exact test), presumably because ultrasound identifies a cannalicular testis in a significant proportion of boys with impalpable testis.

Table 1 summarises the laparoscopic find-

ings. The vas and vessels were demonstrated entering the internal ring in 44 laparoscopic examinations. Subsequent groin exploration identified 13 viable intracanalicular testes, which were treated by conventional orchidopexy with one failure. A small testicular 
Table 1 Laparoscopic findings for 97 impalpable testes

\begin{tabular}{lcl}
\hline Finding & Number & Correlation \\
\hline Vas and vessels entering internal ring & 44 & \\
$\quad$ Viable testis & 13 & \\
Testicular remnant & 22 & \\
Intracanalicular vanished testis & 9 & \\
Vas and vessels stop short of ring & 23 & Intra-abdominal vanished testis \\
Intra-abdominal testis & 27 & \\
$\quad$ Grossly dysmorphic & 4 & \\
Viable & 8 & \\
$\quad$ emergent & 13 & \\
$\quad$ high & 2 & \\
$\quad$ pelvic & 1 & True testicular agenesis \\
Vas and vessels absent & 2 & Exclude high intra-abdominal testis \\
Blind ending vas, no vessels & & before concluding testicle absent \\
& & \\
\hline
\end{tabular}

remnant or nubbin was found at groin exploration in 22 patients, and no remnant (intracanalicular vanished testicle), in the remaining nine explorations.

The vas and vessels were shown to stop short of the internal ring (the intra-abdominal vanished testicle) in 23 examinations. In two patients, a blind ending vas was demonstrated without testicular vessels, and in a single patient both vas and vessels were absent (true testicular agenesis).

There were 27 intra-abdominal testes, including four that were removed at laparoscopy because they were small and grossly dysmorphic. Of the remaining viable testes, eight were classed as emergent (because they could be manipulated into the internal ring at laparoscopy), and were treated by conventional orchidopexy, with three failures. Thirteen were high intra-abdominal (situated above the pelvic inlet at least $3 \mathrm{~cm}$ short of the internal ring), and two were pelvic (situated below the pelvic inlet and more than $3 \mathrm{~cm}$ from the internal ring). Fourteen of the 15 high or pelvic normal intra-abdominal testes were treated by laparoscopic clipping of the testicular vessels. A single low pelvic testis with a short vas was left in situ until puberty, in a patient who had previously undergone a failed open Fowler Stevens orchidopexy for the contralateral intraabdominal testis, before laparoscopy was adopted in our hospital. After puberty, it is planned to remove the testis laparoscopically. Open second stage Fowler Stevens orchidopexies were attempted for 13 intra-abdominal testes, including one patient with bilateral intraabdominal testes, who is currently awaiting a second stage operation for the remaining intraabdominal testis, after a successful laparoscopically assisted Fowler Stevens orchidopexy on the contralateral side. Twelve of the 13 testes were viable at the second stage exploration, and these were all mobilised to a scrotal position. At the most recent follow up, eight were located in the scrotum, and were of unchanged size. Therefore, laparoscopically assisted two stage Fowler Stevens orchidopexy was successful in more than half the patients.

\section{Discussion}

Cryptorchidism is a common finding in paediatric practice. It is encountered in $21 \%$ of preterm male infants, ${ }^{4} 1.8-4 \%$ of all full term boys, ${ }^{5}$ and $0.8 \%$ of 1 year old boys. ${ }^{4}$ The proportion of cryptorchid boys with impalpa- ble testes has been reported to vary from $8.3 \%$ to $20 \% .^{26}$ Despite surgical treatment, unilateral and, to a greater extent, bilateral cryptorchid patients have reduced fertility in adult life, ${ }^{78}$ although seminal analysis has confirmed overall improved fertility following orchidopexy. ${ }^{8}$ In boys treated for impalpable testes, subfertility is even more prevalent. High rates of azoospermia are found in patients after successful treatment of intra-abdominal testes. ${ }^{9}$ Early orchidopexy might halt progressive degenerative changes of seminiferous tubules, ${ }^{10}{ }^{11}$ but there is no conclusive evidence that early orchidopexy improves future fertility, although data are lacking for orchidopexy performed in the second year of life. ${ }^{812}$ The increased risk of testicular cancer in cryptorchid patients is estimated to be 3.8-5.8 overall, ${ }^{13}$ and is higher for those with intraabdominal testes. ${ }^{2}{ }^{14}$ Although there is some evidence that early orchidopexy might reduce the cancer risk, ${ }^{13}$ this has not been demonstrated clearly. ${ }^{815}$ Given these facts, the aim of surgery for the impalpable testis is to locate the testicle if present and, where possible, to bring it to a scrotal position, where it can function in an endocrine capacity, where its contribution to fertility might be improved, and where any malignant change should readily be detected. Any testis that cannot be positioned in the scrotum should be removed after puberty.

A variety of imaging modalities have been used to detect the impalpable testis. These include ultrasound, computed tomography, and magnetic resonance imaging, as well as more invasive procedures such as arteriography and venography. None are as sensitive as laparoscopy for accurate localisation of the intraabdominal testis. ${ }^{5616}$ Laparoscopy was introduced as a diagnostic technique for the impalpable testis by Cortesi in $1976,{ }^{17}$ and Scott reported the first series in children in $1982 .{ }^{18}$ Before the availability of laparoscopy, diagnosis was combined with definitive surgical treatment, involving groin exploration, followed by either laparotomy or extraperitoneal exploration, if neither testis nor cord structures could be found in the inguinal canal, or in the vicinity of the internal ring. Diagnostic laparoscopy can be performed before groin exploration, with little addition to the operating time, and without complication, provided an open technique is used. Complications following laparoscopy, ${ }^{4-619} 20$ and technical failure, ${ }^{21}$ are invariably related to the Veress needle closed puncture technique, which should be avoided in children.

The key to accuracy in diagnostic laparoscopy is the demonstration of the testicular vessels, indicating the presence of a testicle, at least at some developmental stage. The most common finding is both vas and vessels entering the internal ring. Experience enables the distinction between normal and hypoplastic vessels in this situation, the former finding being predictive of a reasonable testis at subsequent groin exploration. Furthermore, patency of the processus vaginalis determined at laparoscopy, correlates strongly with the presence of a viable testis, whether canalicular, ${ }^{16}{ }^{19}$ or 
intra-abdominal. ${ }^{22}$ Hypoplastic vessels entering the ring are associated with either testicular absence (the intracanalicular vanished testis), or a hypoplastic testicular remnant. The need for groin exploration in this situation has been questioned, ${ }^{23}$ but it is probably wise, in view of the potential risk of malignant change in residual testicular stroma. ${ }^{16} 19212224$ The vas and vessels may stop short of the internal ring (the intra-abdominal vanished testis), as was the finding in about a quarter of the laparoscopic examinations in this report. Occasionally, a blind ending vas is seen without evidence of testicular vessels, and both vas and vessels may be absent (true testicular agenesis). Laparoscopy enables the evaluation of the position, size, and structural normality of intra-abdominal testes, which comprised just over a quarter of the impalpable testes in our study. In terms of therapeutic implications, a distinction should be made between pelvic and high intra-abdominal testes, which both require complex orchidopexy, and the emergent testis, which can readily be manipulated into the internal ring. ${ }^{3} 1923$ The latter can usually be treated by conventional orchidopexy through the groin, ${ }^{3}$ although this was associated with quite a high failure rate in our series. The limiting factor for orchidopexy in
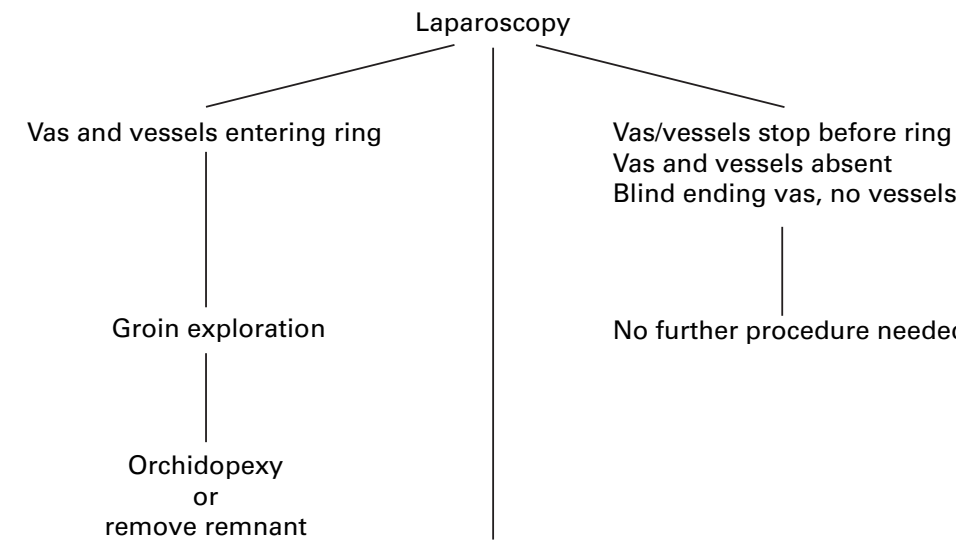

No further procedure needed

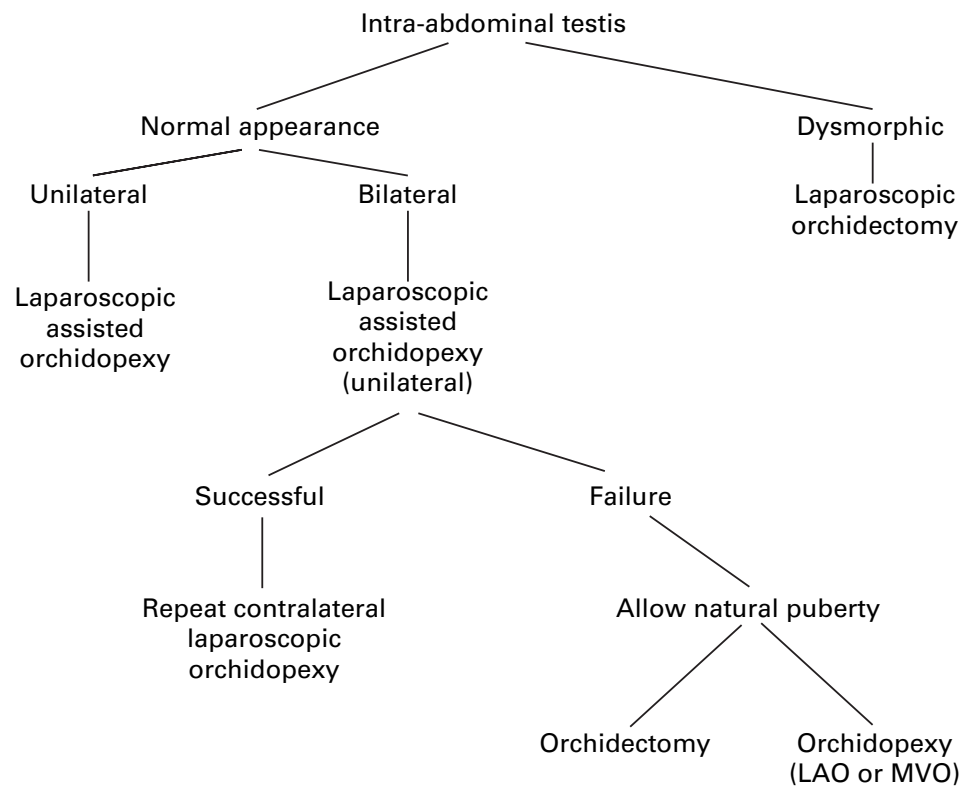

Figure 1 Algorithm for the management of the impalpable testis. the high intra-abdominal testis is the short length of the testicular vessels. These testes require vasal based $^{25} 26$ or microvascular orchidopexy. ${ }^{27}$ In the pelvic testis, the short length of the vas may even preclude complex orchidopexy, ${ }^{5}$ as was the case for a single intraabdominal testis in our series.

Surgical enthusiasm for diagnostic laparoscopy for the impalpable testis should be tempered with a critical analysis of the benefits of the approach, given the extensive surgical experience in the pre-laparoscopic era. Despite reports questioning the need for laparoscopy, ${ }^{1-3}$ it is apparent that laparotomy can be avoided when the intra-abdominal vanished testis is recognised at laparoscopy. Similarly, the diagnosis of true testicular agenesis based on the absence both of testicular vessels and the vas arguably makes laparotomy unnecessary. ${ }^{5}$ Furthermore, it has been suggested that preoperative laparoscopic localisation of an intraabdominal testis facilitates the planning of definitive open surgery. ${ }^{521}$ Taking these factors into consideration, it is estimated that 12.5$47 \%$ of patients with impalpable testis might benefit from diagnostic laparoscopy. ${ }^{1}{ }^{19} 2021$ (These benefits are inferred rather than proved, because control data for similar groups of children managed without laparoscopy are not available in this and most other studies.) In common with other reports, ${ }^{50}$ the laparoscopic identification of intra-abdominal testes in just under a half of the patients subjected to previous groin exploration in our study questions the validity of considering open surgery to be the diagnostic gold standard for the impalpable testis.

In evaluating the potential advantages of laparoscopy over conventional surgery, diagnostic laparoscopy was considered beneficial in just under half of our cases of impalpable testis, including 26 absent testes (where the vas and vessels failed to enter the internal ring), and 19 intra-abdominal testes (excluding the emergent group). Therapeutic laparoscopic interventions, including orchidectomy and laparoscopically assisted two stage orchidopexy, ${ }^{3-6} 19$ were performed in about one fifth of our study group, according to the treatment algorithm outlined in fig 1. Expertise in laparoscopy should be concentrated in units seeing sufficient numbers of patients, both to maintain diagnostic accuracy, and to optimise results of laparoscopic interventional procedures.

1 Wright JE. Impalpable testes: a review of 100 boys. $\mathcal{F}$ Pediatr Surg 1986;21:151-3.

2 Zerella JT, McGill LC. Survival of nonpalpable undescended testicles after orchidopexy. F Pediatr Surg 1993;28: 251-3.

3 Ferro F, Lais A, Gonzalez-Serva L. Benefits and afterthoughts of laparoscopy for the nonpalpable testis. F Urol 1996;156:795-8.

4 Poenaru D, Homsy YL, Peloquin F, et al. Laparoscopic management of the impalpable abdominal testis. Urology 1993;42:574-8

5 Froeling FM, Sorber MJ, de la Rosette JJ, et al. The non palpable testis and the changing role of laparoscopy. Urology 1994;43:222-7.

6 Heiss KF, Shandling B. Laparoscopy for the impalpable testis: experience with 53 testes. F Pediatr Surg 1992;27: 175-8.

7 Kogan SJ. Fertility in cryptorchidism. An overview in 1987 Eur $\mathcal{F}$ Pediatr 1987;146(Suppl 2):21-4.

8 Chilvers C, Dudley NE, Gough MH, et al. Undescended testis: the effect of treatment on subsequent risk of subfertestis: the effect of treatment on subsequent risk of subf
tility and malignancy. $\mathcal{F}$ Pediatr Surg 1986;21:691-6. 
9 Puri P, O’Donnell B. Semen analysis of patients who had orchidopexy at or after seven years of age. Lancet

10 Mengel W, Heinz HA, Sippe WG, et al. Studies on cryptorchidism: a comparison of histological findings in the germinative epithelium before and after the second year of life. F Pediatr Surg 1974;9:445-50.

11 Hadziselimovic F, Herzog B, Höcht B, et al. Screening for cryptorchid boys risking sterility and results of long-term buserelin treatment after successful orchidopexy. Eur $\mathcal{F}$ Pediatr 1987;146(Suppl 2):59-62

12 Cotes D, Thorup JM, Lindenberg S. Fertility potential after unilateral orchidopexy: an age independent risk of subsequent infertility when biopsies at surgery lack germ cells. F Urol 1996;156:217-20.

13 United Kingdom Testicular Cancer Study Group. Aetiology of testicular cancer: association with congenital abnormalities, age at puberty, infertility, and exercise. BMF 1994;308: ties, age $1393-9$.

14 Stone JM, Cruickshank DG, Sandeman TF, et al. Laterality, maldescent, trauma and other clinical factors in the epidemiology of testis cancer in Victoria, Australia. Br 7 Cancer $1991 ; 64: 132-8$

15 Pike MC, Chilvers C, Peckham MJ. Effect of age at orchidopexy on risk of testicular cancer. Lancet 1986;8492 1246-8.

16 Tennenbaum SY, Lerner SE, McAleer IM, et al. Preoperative laparoscopic localization of the nonpalpable testis: critical analysis of a 10 year experience. F Urol $1994 ; 151$ 732-4.

17 Cortesi N, Ferrari P, Zambarda E, et al. Diagnosis of bilateral abdominal cryptorchidism by laparoscopy. Endoscopy 1976;8:33-4.
18 Scott JES. Laparoscopy as an aid in the diagnosis and management of the impalpable testis. F Pediatr Surg 1982;17: 14-16.

19 Vaysse P. Laparoscopy and impalpable testis-a prospective multicentric study (232 cases). GECI. Groupe d'Etude en Coeliochirurgie Infantile. Eur f Pediatr Surg 1994;4:32932.

20 Diamond DA, Caldamone AA. The value of laparoscopy for 106 impalpable testes relative to clinical presentation. $\mathcal{f}$ Urol 1992;148:632-4.

21 Moore RG, Peters CA, Bauer SB, et al. Laparoscopic evaluation of the nonpalpable testis: a prospective assessment of accuracy. $\mathcal{F}$ Urol 1994;151:728-31.

22 Elder JS. Laparoscopy for impalpable testes: significance of the patent processus vaginalis. F Urol 1994;152:776-8.

23 Guiney EJ, Corbally M, Malone PS. Laparoscopy and the management of the impalpable testis. Br F Urol 1989;63: 313-16.

24 Plotzker ED, Rushton HG, Belman AB, et al. Laparoscopy for nonpalpable testes in childhood: is inguinal exploration also necessary when vas and vessels exit the inguinal ring? $f$ Urol 1992;148:635-7.

25 Fowler R Jr, Stephens FD. The role of testicular vascular anatomy in the salvage of high undescended testes. Aust $N$ Z F Surg 1959;29:92-106.

26 Ransley PG, Vordermark JS, Caldamone AA, et al. Preliminary ligation of gonadal vessels prior to orchidopexy for the intra-abdominal testicle. World $\mathcal{F}$ Urol 1984;2:266-8.

27 Silber SJ, Kelly J. Successful autotransplantation of an intraabdominal testis to the scrotum by microvascular technique. $\mathcal{F}$ Urol 1976;115:452-4. 